\title{
EHMTI-0063. The migraine disability assessment (MIDAS) questionnaire: translation, validation and reliability of Bahasa Melayu version
}

\author{
MM Shaik*, NB Hassan², HL Tan', SH Gan \\ From 4th European Headache and Migraine Trust International Congress: EHMTIC 2014 \\ Copenhagen, Denmark. 18-21 September 2014
}

\section{Introduction}

MIDAS has become a popular and useful tool for evaluating migraine-related disability worldwide.

\section{Aim \\ The study was designed to determine the validity and relia- bility of the Bahasa Melayu version (MIDAS-M) of the Migraine Disability Assessment (MIDAS) Questionnaire.}

\section{Methods}

The patients attending the Neurology Clinic, Hospital Universiti Sains Malaysia, Kubang Kerian, Kelantan, Malaysia, were screened against the inclusion and exclusion criteria. Patients were eligible for the study if they had been diagnosed with migraine for more than six months. Standard forward and back translation procedures were used to translate and adapt the MIDAS Questionnaire to produce the Bahasa Melayu version. The translated Malay version was tested for face and content validity. Validity and reliability testing were further conducted with 100 migraine patients (1st administration) followed by a retesting session 21 days later (2nd administration).

\section{Results}

A total of 100 patients between 15-60 years of age were recruited. The majority of the patients were single (66\%), students $(46 \%)$ and had a severe disability (46\% MIDAS grade IV). The sample was adequate according to the Kaiser-Meyer-Olkin value of 0.75 . The Cronbach's alpha values were 0.84 ( 1 st administration) and 0.80 (2nd administration). The test-retest reliability for the total MIDAS score was 0.73 , indicating that the MIDAS-M

THuman Genome Centre, Universiti Sains Malaysia, Kubang Kerian, Malaysia Full list of author information is available at the end of the article questionnaire is stable; for the five disability questions, the test-retest values ranged from 0.77 to 0.87 .

\section{Conclusion}

The MIDAS-M questionnaire is comparable with the original English version in terms of validity and reliability and may be used for the assessment of migraine in clinical settings.

No conflict of interest.

\section{Authors' details}

${ }^{1}$ Human Genome Centre, Universiti Sains Malaysia, Kubang Kerian, Malaysia. ${ }^{2}$ Department of Pharmacology, Universiti Sains Malaysia, Kubang Kerian, Malaysia.

Published: 18 September 2014

doi:10.1186/1129-2377-15-S1-D56

Cite this article as: Shaik et al:: EHMTI-0063. The migraine disability assessment (MIDAS) questionnaire: translation, validation and reliability of Bahasa Melayu version. The Journal of Headache and Pain 201415 (Suppl 1):D56.

Submit your manuscript to a SpringerOpen ${ }^{\odot}$ journal and benefit from:

- Convenient online submission

- Rigorous peer review

- Immediate publication on acceptance

- Open access: articles freely available online

- High visibility within the field

- Retaining the copyright to your article

Submit your next manuscript at $>$ springeropen.com (c) 2014 Shaik et al; licensee Springer. This is an Open Access article distributed under the terms of the Creative Commons Attribution License (http://creativecommons.org/licenses/by/2.0), which permits unrestricted use, distribution, and reproduction in any medium, provided the original work is properly cited. 